\title{
Asymptomatic Leiomyoma- Is It Belly Fat!!
}

\author{
A. Mehrunnisa Abdul Huq ${ }^{1}$, Jamila Hameed ${ }^{2}$, Muzain Jasim M. P. ${ }^{3}$ \\ ${ }^{1}$ Department of Obstetrics and Gynaecology, Karuna Medical College, Palakkad, Kerala, India. \\ ${ }^{2}$ Department of Obstetrics and Gynaecology, Karuna Medical College, Palakkad, Kerala, India. \\ ${ }^{3}$ Department of Obstetrics and Gynaecology, Karuna Medical College, Palakkad, Kerala, India.
}

\section{PRESENTATION OF CASE}

A thirty-nine-year-old lady P2 L2 admitted with lower abdominal mass since 3 months had no history of menstrual problems and pressure symptoms. ${ }^{1}$ The uterus was palpable which was of 34 weeks size. She had a scar in subumbilical region for puerperal sterilization which was done 17 years ago after her second childbirth. Medical and surgical history was unremarkable. Routine investigations like urine examination including culture, $\mathrm{CBC}$, clotting profile, kidney function test, $\mathrm{x}$-ray chest, ECG were within normal limits. PAP smear and vaginal swab were normal. USG shows $14.1 \mathrm{~mm} \times 10.6 \mathrm{~cm}$ fibroid occupying posterior fundal wall. There is another fibroid measuring $7.5 \mathrm{~cm} \times 6.5 \mathrm{~cm}$ in the anterior wall in the body of uterus, other three small fibroids $5.5 \mathrm{~cm}$ x $4.5 \mathrm{~cm}$, endometrial thickness normal, both ovaries appear normal, no hydroureters, no degeneration or calcification were noted.

The name "fibroid" is a misnomer, leiomyoma is the correct nomenclature since it is made of smooth muscles and connective tissue. The accumulative life time risk is $75 \%$. It is a benign monoclonal tumour and is asymptomatic in about $50 \%$ of cases. It is unusual to have such huge fibroids without any symptoms. The patient having such huge multiple intra mural fibroids without any complaints is really a wonder. Nowadays, in the era of advanced technology ultrasound can even pick small seedlings of fibroid, it is a rare finding especially in urban areas. Since it has no impact on the day to day activities, the patient had no complaints.

Fibroid size usually does not determine the severity of symptoms. But the site of the fibroid matters a lot, the woman with intramural fibroid will be having menstrual problem but the broad ligament, cervical and submucous fibroid show no menstrual problems. Pelvic pain, post-coital bleeding and dyspareunia, are the chief complaints in cervical fibroids. The anatomy of the uterus is altered in broad ligament fibroids and in cervical fibroids. Infertility is noted in case of submucous fibroid especially recurrent abortion and preterm delivery. During labour, caesarean section may be needed for fibroid complicating during pregnancy causing dystocia. Ultrasound and MRI are the gold standards in diagnosis and differential diagnosis. The ideal modality of treatment for our patient was total hysterectomy since she has completed her family not insisted on retaining her uterus.
Corresponding Author: Dr. Jamila Hameed,

Department of Obstetrics and Gynaecology, Karuna Medical College, Palakkad,

Kerala, India.

E-mail: jamilahameed@gmail.com

DOI: $10.14260 / \mathrm{jemds} / 2020 / 331$

Financial or Other Competing Interests: None.

How to Cite This Article:

Huq AMA, Hameed J, Jasim MMP. Asymptomatic leiomyoma- is it belly fat!!! J. Evolution Med. Dent. Sci. 2020;9(18):15191521, DOI: 10.14260/jemds/2020/331

Submission 04-03-2020,

Peer Review 15-04-2020,

Acceptance 23-04-2020,

Published 04-05-2020.

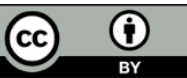


An irregularly enlarged uterus wherein the upper boarder and the lateral borders felt. The uterus was as big as 34 weeks pregnancy. The surface was irregular, nodular, bossed, nontender, firm, movable from side to side, lower boarder not felt. Cervix moves along with uterus- transmitted movement positive, USG confirmed the diagnosis MRI not done as we planned for hysterectomy for our patient. Other investigations CA-125 was not done as clinically ruled out the possibility of ovarian tumour and patient is still a menstruating lady.

Usually menstrual symptoms like menorrhagia, menometrorrhagia, ${ }^{2}$ dyspareunia, in fertility, retention of urine, frequency of urine, rectal symptoms and oedema of legs are associated with leiomyomas. Abdominal pain is associated with degeneration of the fibroid. The sarcomatous degeneration is very rare only about $0.1 \%$ also associated with pain, sudden growth wherein the whorl appearance and capsule are lost. This fibroid was non-tender and firm "in spite of the sudden increase in size" but the patient explains as "belly fat". The patient has not felt any kind of impact on her day to day life.

\section{DIFFERENTIAL DIAGNOSIS}

1. Pregnancy.

2. Bladder.

3. Ovarian tumour.

4. Adenomyosis.

\section{PATHOLOGICAL DISCUSSION}

These are benign tumours of smooth muscle and occur only during reproductive age signifies the growth depends on ovarian steroid hormones like oestradiol and progesterone. The exact aetiology is an enigma. On macroscopic appearanceit is usually firm, rubbery, appears with pseudo capsule. Microscopic picture-shows spindle muscles are arranged in bundles intervening with fibrous tissue ${ }^{3}$. On degeneration, features like-hyaline, cystic and calcareous types of degeneration can be seen. Mitotic activity more than 10 mitosis per HPF without atypia or necrosis shows benign in nature. Sometimes such high mitotic index without atypia maybe a feature of several histological variety of leiomyoma.

The other types of investigation for diagnosis other than USG is MRI which very useful for mapping out the different site, size, number and depth, nature of the lesion and the associated pelvic pathology. Adenomyosis which is an important condition of internal endometriosis may be associated with fibroid can be easily distinguished from fibroid. Adenomyosis usually a uniform, tender, soft, cystic swelling growing not more than 16 week size unlike fibroid which is firm, non-tender unless it has undergone degeneration.

Saline hysterosonography- to make out submucous fibroid to standout clearly.

Hysterosalpingography- wherein dye is injected into the uterine cavity and fallopian tube and X-ray images taken

Hysteroscopy is not only diagnostic but also therapeutic for excision of submucous fibroid
Laparoscopy- especially for sub-serous fibroids excision.

\section{DISCUSSION OF MANAGEMENT}

Not a single best option exists ${ }^{4}$, depends on age, site of tumour, parity, the choice of the patient and the symptoms exhibited. Fibroid grows slowly and it shrinks after menopause. The surgical treatment is the topmost standard option for women who do not wish to retain uterus for fertility. The medical management is ideal if patient has menstrual and pressure symptoms.

GnRh agonist ${ }^{5}$ help to shrink the fibroid but takes a long time about six months which make the patient in a hypoestrogenic phase. The fibroid grows back again after the treatment is stopped. And it is expensive also. There is a fear of osteoporosis so usually add-back therapy with Tibilone is given. NSAIDS reduce bleeding so also Tranexamic acid, combined oral contraceptives, progesterone releasing IUCDS (Mirena). ${ }^{6}$

Other modality of treatments - non-invasive procedure like MRI guided high intensity focused ultrasound is done in an outpatient basis. The minimal invasive procedures like uterine artery embolization ${ }^{7}$ with embolizing agents like polyvinyl alcohol gel is injected into femoral artery, is effective in shrinkage of fibroid but not a suitable method for patients having infertility. Laparoscopic myomectomy, hysteroscopic myomectomy - by morcellation, robotic surgery ${ }^{8}$ is also available in higher centers.

The cornerstone of management is hysterectomy. In our patient the age, parity, the site and size of the fibroid warranted hysterectomy. The patient also insisted on hysterectomy. Total hysterectomy was done with only a single unit of blood transfusion intra-operatively. The surgery was done without any complications. The post-operative period was also uneventful.

The specimen is sent to pathology department to confirm the diagnosis of leiomyoma. The specimen shows - Gross appearance: uterus with cervix and weighs appr. $2.86 \mathrm{~kg}$. Uterus measuring $20 \mathrm{~cm} \times 17 \mathrm{~cm} \mathrm{x} 9 \mathrm{~cm}$ and cervix measures $4.5 \mathrm{~cm} \times 2.5 \mathrm{~cm} \times 1 \mathrm{~cm}$. Fundal intramural fibroid measuring 17 $\mathrm{cm} \times 12 \mathrm{~cm}$ with whorl like cut surface. Endometrial canal length is $4 \mathrm{~cm}$. Endometrial thickness is $2 \mathrm{~mm}$ and average myometrial thickness is $2 \mathrm{~cm}$. Four separate masses - Largest measures $7.5 \mathrm{~cm} \times 6.5 \mathrm{~cm} \times 3.5 \mathrm{~cm}$ and smallest measures 5.5 $\mathrm{cm} \mathrm{x} 4.5 \mathrm{cms} .1 .5 \mathrm{~cm}$. External surface appears smooth and cut surface of all tissues shows whorl like surface.

\section{Microscopic Appearance and Diagnosis}

a. Cervix: Shows ectocervix with features hyperplasia and hyperkeratosis. Endocervix shows papillary endocervicitis with few cystically dilated glands. No evidence of intraepithelial lesion and malignancy.

b. Uterine Wall and Fibroid: Shows endometrium in proliferative phase with intramural leiomyoma. No evidence of atypia or atypical mitosis or necrosis.

c. Separately Sent Soft Tissue Masses: shows features consistent with leiomyomata. No evidence of atypia or atypical mitosis or necrosis. 


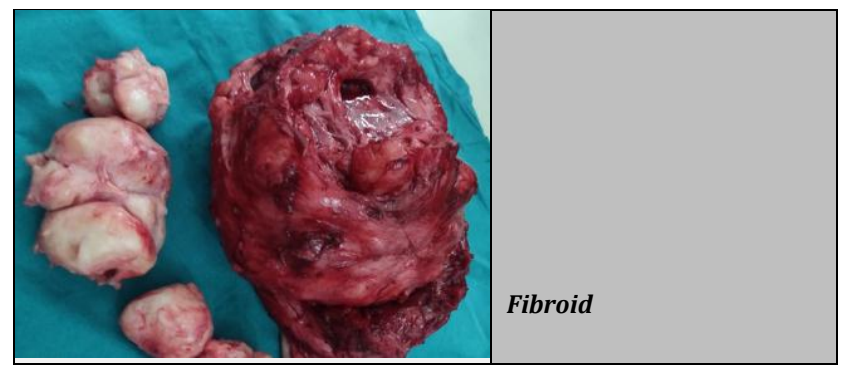

REFERENCES

[1] Geetha K, Hameed J, Seethalakshmi, et al. A huge parasitic fibroid causing hernia. Journal of Evolution of Medical and Dental Sciences 2014;3(28):7807-10.

[2] Wegienka G, Baird DD, Hertz-Picciotto I, et al. Selfreported heavy bleeding associated with uterine leiomyomata. Obstet Gynecol 2003;101(3):431-7.
[3] Holdsworth-Carson SJ, Zaitseva M, Vollenhoven BJ, et al. Clonality of smooth muscle and fibroblast cell populations isolated from human fibroid and myometrial tissues. Mol Hum Reprod 2014;20(3):250-9.

[4] Zimmermann A, Bernuit D, Gerlinger C, et al. Prevalence, symptoms and management of uterine fibroids: an international internet-based survey of 21,746 women. BMC Womens Health 2012;12:6.

[5] Donnez J, Tomaszewski J, Vázquez F, et al. Ulipristal acetate versus leuprolide acetate for uterine fibroids. $\mathrm{N}$ Engl J Med 2012;366(5):421-32.

[6] Sangkomkamhang US, Lumbiganon P, Lapaiboon M, et al. Progestogens or progestogen-releasing intrauterine fibroids. Cochrane Database Syst Rev 2013;(2):CD008994.

[7] Gupta JK, Sinha A, Lumsden MA, et al. Uterine artery embolization for symptomatic uterine fibroids. Cochrane Database Syst Rev 2014;(12):CD005073.

[8] Donnez J, Dolmans MM. Uterine fibroid management: from the present to the future. Hum Reprod Update 2016;22(6):665-86. 